\title{
A comparison of the onset time of complete blockade of the sciatic nerve in the application of ropivacaine and its equal volumes mixture with lidocaine: a double-blind randomized study
}

\author{
Piacherski Valery, and Marochkov Aliaksei \\ Department of Anesthesiology Intensive Care, Mogilev Regional Hospital, Mogilev, Republic of Belarus
}

Background: The purpose of the current study is to create a new mixture of local anesthetics-one with a short time of block development and short action term ( $5 \mathrm{ml}$ of $1 \%$ lidocaine solution) and another with a longer time of anesthesia development and a long analgetic effect ( $5 \mathrm{ml}$ of $0.75 \%$ ropivacaine)-for use during surgical operations on extremities. The primary end point was the development of the complete sensory block of the sciatic nerve.

Methods: Sixty blocks of sciatic nerve were used in a double-blind randomized research, under ultrasonic guidance, using an electric stimulator with the peripheral nerves. Sixty patients were divided into 3 equal groups. In the first group, a sciatic nerve block was performed with $5 \mathrm{ml}$ of $0.75 \%$ ropivacaine solution $(37.5 \mathrm{mg})$; in the second group, $10 \mathrm{ml}$ of $0.75 \%$ ropivacaine solution $(75 \mathrm{mg}$ ) was used and, in the third group, a mixture of $5 \mathrm{ml}$ of $0.75 \%$ ropivacaine (as above) and 5 $\mathrm{ml}$ of $1 \%$ lidocaine solution $(50 \mathrm{mg}$ ) was used. The assessment of the time required for developing sensory and motor blocks was carried out from the beginning of local anesthetic solution injection in the fascial sheath of the sciatic nerve.

Results: Demographic data of patients were identical in the three sample groups. The time required for achieving a complete motor and sensory block was reduced due to the mix of the $1 \%$ lidocaine solution with the $0.75 \%$ ropivacaine solution. The time required for achieving a complete sensory block in groups treated with 5 and $10 \mathrm{ml}$ ropivacaine was 45 (40-48) and $30(28-30)$ min, respectively, in contrast with $12(10-13)$ min when the mixture of anesthetics was applied $(\mathrm{P}<0.01)$. There was no difference in analgesic duration in the postoperative period among groups at $\mathrm{P}>0.05$.

Conclusions: The mixture of $5 \mathrm{ml}$ of $1 \%$ lidocaine with $5 \mathrm{ml}$ of $0.75 \%$ ropivacaine leads to a reduction in the time required for the development of complete sensory and motor blocks of the sciatic nerve, without reducing postoperative analgesia time. (Korean J Anesthesiol 2013; 65: 42-47)

Key Words: Lidocaine, EMLA, Ropivacaine, Sciatic nerve, Ultrasonography.

Received: August 14, 2012. Revised: 1st, October 1, 2012; 2nd, December 31, 2012; 3rd, January 3, 2013. Accepted: January 9, 2013.

Corresponding author: Piacherski Valery, M.D., Department of Anesthesiology Intensive Care, Mogilev Regional Hospital, 3-36, A. Kuleshov str., Mogilev 212026, Republic of Belarus. Tel: 375-445-378157, Fax: 375-445-278698, E-mail: pechersky.v@yandex.ru

(c) This is an open-access article distributed under the terms of the Creative Commons Attribution Non-Commercial License (http:// creativecommons.org/licenses/by-nc/3.0/), which permits unrestricted non-commercial use, distribution, and reproduction in any medium, provided the original work is properly cited. 


\section{Introduction}

An anesthetist's arsenal includes several local anesthetics for carrying out regional anesthesia, and these anesthetics require different times for achieving complete sensory and motor blocks as well as different acting times [1]; attempts to mix anesthetics with different properties were done earlier with the aim of summarizing their useful effects. The toxic action of local anesthetics, appearing as a result of unpremeditated intravascular injection as well as a result of preparation absorption, required research in order to identify low doses of local anesthetics for effectively blocking peripheral nerves [2].

Discrepant results have been published about the application of mixtures of various anesthetics for sciatic nerve block. Cuvillon et al. [3] noted that, if $20 \mathrm{ml}$ of $0.75 \%$ ropivacaine ( 150 $\mathrm{mg}$ ) is mixed with $20 \mathrm{ml}$ of $2 \%$ lidocaine (with the addition of epinephrine at a ratio of $1: 200,000$ ), the time required for the blockade of the sciatic nerve beginning shortens significantly. However, the complete block developed in these observations to the 30th minute. Related to previous eye surgeries, a report was published that the time for the development and blockade duration compared when retrobulbar block was performed with ropivacaine and using a mixture $(1: 1)$ of bupivacaine and lidocaine [4]. Chelly [5] wrote that, to achieve surgical anesthesia of the sciatic nerve, 15-20 min are required if ropivacaine $0.75 \%$ is used and $10-20 \mathrm{~min}$ if $0.75 \%$ ropivacaine is mixed with $1.5 \%$ lidocaine. Although the report's author did not describe the amount, volume, and proportion of anesthetics, data were included about the quicker development of sensory block if lidocaine is mixed with bupivacaine for epidural blockade performance [6]. Data related to the application of preparation mixtures for peripheral blocks are very scarce. Taking into account the highly contradictory character of the available data about the effectiveness and expediency of local anesthetics mix as well as the opportunity to apply ultrasonic visualization during block performance, we see the need for a more detailed study into this problem.

The purpose of the double-blind randomized study was to measure the time required for the achievement of the complete sensory block of the sciatic nerve (sensory block as a result of local anesthetics mixture application: primary end point), postoperative analgesia duration, and time for the development of the sciatic nerve motor block (secondary end point), if ropivacaine is used and in comparison with the ropivacaine-lidocaine mixture in patients undergoing orthopedic and traumatologic operations.

\section{Materials and Methods}

Ethical approval for this study was acquired by the Ethical Committee of the Mogilev Regional Hospital, Belarus (President
Dr. Alexandr R. Stolin), Protocol No. 30 on 5 September 2011. Patients were randomized before the operation with respect to the manner of sciatic nerve block using one of three solutions, whose descriptions were randomly placed in sealed envelopes prior to the operation. To determine the effect of the anesthetics mix, we created three groups of patients, with 20 anesthesia performances in each group A: block with $5 \mathrm{ml}$ of $0.75 \%$ ropivacaine group B: block with $10 \mathrm{ml}$ of $0.75 \%$ ropivacaine, and group C: block with $5 \mathrm{ml}$ of $0.75 \%$ ropivacaine + $5 \mathrm{ml}$ of $1 \%$ lidocaine. The block was performed for patients before the operation on account of post-traumatic injuries and the dysfunction of shin bones, the genu joint, the talocrural joint, and foot, moving the metal constructions away from the shin bones.

The criteria for the inclusion of patients in the research included destination to an operation requiring anesthesia and the presence of the patient's written informed consent for the kind of anesthesia and its probable complications. The criteria for the exclusion of patients included the patient's refusal to take the proposed kind of anesthesia, patients who are too young (age $<18$ ) or small (weight $<50 \mathrm{~kg}$ ), patients with a physical status value of ASA $>3$, patients with allergic reactions to the applied medications in anamnesis, coagulopathy, infectious skin lesions at the injection area, neurological or nerve-muscular diseases, heavy liver diseases or kidney deficiency, and the inability to cooperate in the process. The characteristics of the groups are shown in Table 1.

All anesthetic solutions were prepared by the anesthesiologist, who did not take part in the research. The composition of the solutions was as follows:

$$
\begin{aligned}
& \text { solution A: } 5 \mathrm{ml} \text { ropivacaine - } \mathrm{HCl}-0.75 \%(37.5 \mathrm{mg}) \\
& \text { solution B: } 10 \mathrm{ml} \text { ropivacaine - } \mathrm{HCl}-0.75 \%(75 \mathrm{mg}) \\
& \text { solution C: } 5 \mathrm{ml} \text { ropivacaine - } \mathrm{HCl}-0.75 \%(37.5 \mathrm{mg})+ \\
& 5 \mathrm{ml} \text { lidocaine - } \mathrm{HCl}-1 \%(50 \mathrm{mg})
\end{aligned}
$$

With the aim of premedication, $0.5-0.8 \mathrm{mg}$ of atropine and $10 \mathrm{mg}$ of Diphenhydramine were injected intramuscularly 2030 min before the block. All patients received injections via venous access through catheter installation in a peripheral vein. $\mathrm{SpO}_{2}$, electrocardiogram, and non-invasive arterial pressure

Table 1. Characteristics of the Studied Patient Groups

\begin{tabular}{lccc}
\hline & $\mathrm{A}$ & $\mathrm{B}$ & $\mathrm{C}$ \\
& $(\mathrm{N}=20)$ & $(\mathrm{N}=20)$ & $(\mathrm{N}=20)$ \\
\hline Age (yr) & $42(25-46)$ & $41(37-39)$ & $42(28-55)$ \\
Body weight (kg) & $80(60-85)$ & $78(70-85)$ & $74(59-86)$ \\
Sex (M/F) & $17 / 3$ & $12 / 8$ & $16 / 4$ \\
\hline
\end{tabular}

Group A: block with $5 \mathrm{ml}$ of $0.75 \%$ ropivacaine, Group B: block with 10 $\mathrm{ml}$ of $0.75 \%$ ropivacaine, Group C: block with $5 \mathrm{ml}$ of $0.75 \%$ ropivacaine $+5 \mathrm{ml}$ of $1 \%$ lidocaine. The data were figured as median and quartiles (25th and 75 th percentiles). 
were monitored. In order to sedate the patients, depending on their emotional state, $10 \mathrm{mg}$ of Diazepam and/or $0.1 \mathrm{mg}$ of Fentanyl was injected intravenously several minutes after the operation began.

Sciatic nerve block was performed using a posterior approach, with the patient lying on his/her belly, under ultrasonic control [7]. The Aloca SSC400 apparatus with an ultrasonic detector of $7.5 \mathrm{MHz}$ was used for visualization. After getting a picture of the sciatic nerve, a $100 \mathrm{~mm}$ isolated injection needle (Stimuplex ${ }^{\circledR}, \mathrm{B}$. Braun Melsungen AG, Germany) connected to a neurostimulator (HNS 11, B Braun) was used to approach the nerve trunk until the appropriate group of muscles responded. The initial current strength was $0.4 \mathrm{~mA}$ (frequency $1 \mathrm{~Hz}$, impulse length $100 \mu \mathrm{sec}$ ). After the muscular response and aspiration probe execution, a solution of local anesthetic was injected into the fascial sheath of the sciatic nerve ("fascial plane concept") [8]. All blockades were performed under ultrasonic guidance, and in all cases we observed a "doughnut sign" effect. The method was completely blind as the anesthetist who performed the blockage did not see the syringe with the anesthetic. The syringe was in an assistant's hand behind a screen. The beginning of the solution injection was designated as zero point for the time control. In all cases for providing operations on extremities, an additional block of the femoral nerve using a " 3 -in-1" block was performed, depending on the region of the surgical operation [9]. The additional block was carried out in the same manner-with $25 \mathrm{ml}$ of lidocaine $1 \%$ with the addition of epinephrine $(1: 200,000)$. The quality of the femoral nerve block or lumbar plexus branches (obturative nerve, lateral cutaneous nerve of hip, femoral nerve) block was assessed at once after $15 \mathrm{~min}$.

The primary end point of the research was the point in time when complete sensory block was achieved. A cutaneous sensitivity assessment was carried out every 2 min until the 65th min of the block. The following scale was used for sensory block assessment: ' ++' - complete sensory block (anesthesia); '+' incomplete sensory block, patient is not able to differentiate the type of irritant; and '-' - cutaneous sensitivity is fully preserved. Assessment of the patient's reaction was made using a pinprick test.

The secondary end points in this research were the complete motor block and the end of the analgetic effect of the blockade. Motor block assessment was carried out every 2 min until the 65th min after the local anesthetic injection, using the following scale: ' ++ ' - movements totally absent; ' + ' - movements preserved partly or not coordinated; '-' - movements fully preserved. Patients were asked to do a plantar flexion of the foot-tibial nerve and dorsiflexion with the common peroneal nerve. Both sensitivity and motor activity assessments were carried out by an independent anesthesiologist who did not take part in the research.

The duration of the postoperative analgesia was assessed through inquiry of the patient after surgery. Inquiry was done every $30 \mathrm{~min}$ by an independent anesthesiologist who did not take part in the research. The moment the patient started to complain about the sensation of pain in the operated region was noted as the end point of the regional block analgetic effect. Pain sensation was assessed according to the visual analogous scale (VAS), ranging from $0 \mathrm{~mm}$ (no pain) to $10 \mathrm{~mm}$ (intolerable pain). When pain sensation occurred in the region of the postoperative wound (1-2 points), $1 \mathrm{ml}$ of $2 \%$ promedol was injected intramuscularly at $6 \mathrm{~h}$ intervals as an analgesia. We did not register the duration of the sensory and motor blocks.

Statistic processing of the data was carried out using Statistica 7.0 software. Three groups of patients were compared using the non-parametric method of a Kruskal-Wallis ANOVA. The zero hypothesis about the absence of differences was accepted when $\mathrm{P}>0.05$. If $\mathrm{P}<0.05$, the zero hypothesis was rejected, the differences between groups were accepted as statistically significant and a pairwise comparison of the groups was carried out using a non-parametric Mann-Whitney test. The data were figured as median and quartiles $\left(25^{\text {th }}\right.$ and $75^{\text {th }}$ percentiles).

\section{Results}

The research involved 60 patients. No differences existed between groups in terms of gender, body weight, age, or ASA classification. In all patients, the sciatic nerve was localized using ultrasonic pointing, and muscular response to electric stimulation was achieved. During anesthesia, the indices for $\mathrm{SPO}_{2}$, electrocardiogram, and non-invasive arterial blood pressure did not decline from normal rates (the data are not provided here).

The complete sensory block $(++)$ developed after 45 (4048) min in group A, after 30 (28-30) min in group B, and after 12 (10-13) $\mathrm{min}$ in group C (Fig. 1). Reliable differences were observed among groups, $\mathrm{P}<0.05(\mathrm{P}=0.000)$.

The time for motor block development was 55 (50-60) $\mathrm{min}$ in group A, 35 (34-37) min in group B, and 14 (12-17) min in group C. We noted a reliable decrease in time as required for achieving the complete motor block of the sciatic nerve (Fig. 2). The differences among the groups were reliable, $\mathrm{P}<0.05(\mathrm{P}=0.000)$.

Regional anesthesia duration in the postoperative period was 8 (7.5-8.0) h for patients in group A, 8 (7.0-8.5) h for patients in group $\mathrm{B}$, and $8(7.0-8.5) \mathrm{h}$ for patients in group C. No reliable differences in anesthesia duration occurred among the groups at $\mathrm{P}>0.05(\mathrm{P}=0.82)$.

\section{Discussion}

As stated by Taboada et al. [10], during sciatic nerve block using the subgluteal approach, the minimal volume for anes- 


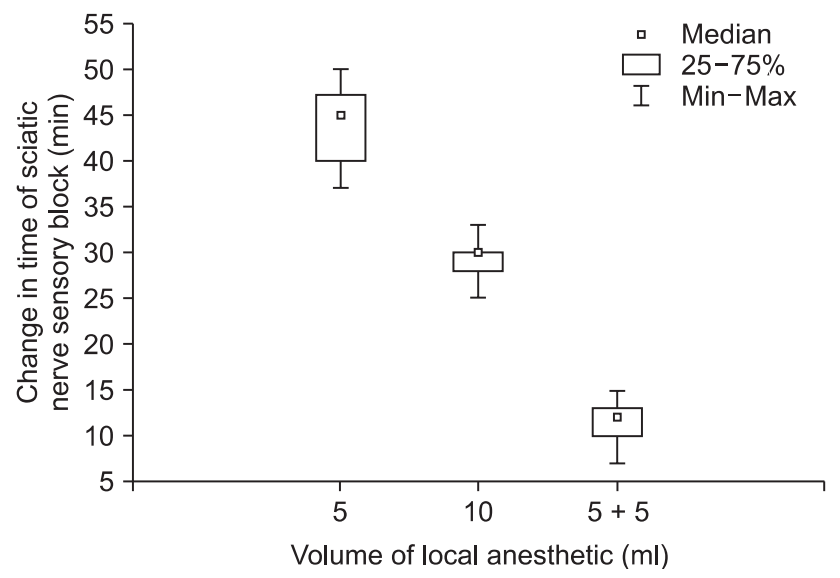

Fig. 1. Change in onset time of sciatic nerve sensory block achievement depending on the applied solutions. Horizontal axis: the kind of solution $(5 \mathrm{ml}=5 \mathrm{ml}$ of $0.75 \%$ ropivacaine; $10 \mathrm{ml}=10 \mathrm{ml}$ of $0.75 \%$ ropivacaine; $5+5=$ mixture of $5 \mathrm{ml}$ of $0.75 \%$ ropivacaine and $5 \mathrm{ml}$ of $1 \%$ lidocaine); vertical axis: time of sensory block, approaching min.

thesia development is $12 \pm 3 \mathrm{ml}$ of $1.5 \%$ mepivacaine. Latzke et al. [11] found that, for successfully blocking the sciatic nerve at the level of middle hip, the sufficient volume of the local anesthetic is less than $5 \mathrm{ml}$ (1.5\% mepivacaine). Our data showed that application of $5 \mathrm{ml}$ of $0.75 \%$ ropivacaine in the gluteal area leads to a complete blockage of the sciatic nerve. Thus, we succeed to reduce the volume of $0.75 \%$ ropivacaine to $5 \mathrm{ml}$ and reduce the amount to $37.5 \mathrm{mg}$ while retaining the effective blockage of the sciatic nerve.

In our opinion, reducing the time required for the complete block development in group B compared to group A is associated with the application of twice as much ropivacaine in $\mathrm{B}$ as in A. The available literature data concerning this area of anesthesia is extensive. Previously published data obtained during the blockage of the humeral plexus by using the axillary approach showed that the rate of anesthesia development does not depend on the amount (mg) of local anesthetic [12,13]. Slower development of motor and sensory block was noted by Riazi et al. [14], when $5 \mathrm{ml}$ of ropivacaine was applied instead of $20 \mathrm{ml}$ in the humeral plexus blockage. It should be noted that these data were obtained in the blockage of nerves with a small diameter. Taboada Muniz et al. [15] stated that the application of different volumes and concentrations of local anesthetic in sciatic nerve block according to Labat changes the time of anesthesia. As noted by Latzke et al. [11], the amount of anesthetic in sciatic nerve blockage has not yet been shown to have an effect on the time of sensory block development, but this aspect, as the author wrote, needs additional research.

According to Moayeri and Groen [16], the proportion of non-neural and neural tissue in the sciatic nerve is a factor influencing the rate of block development. In addition, the more

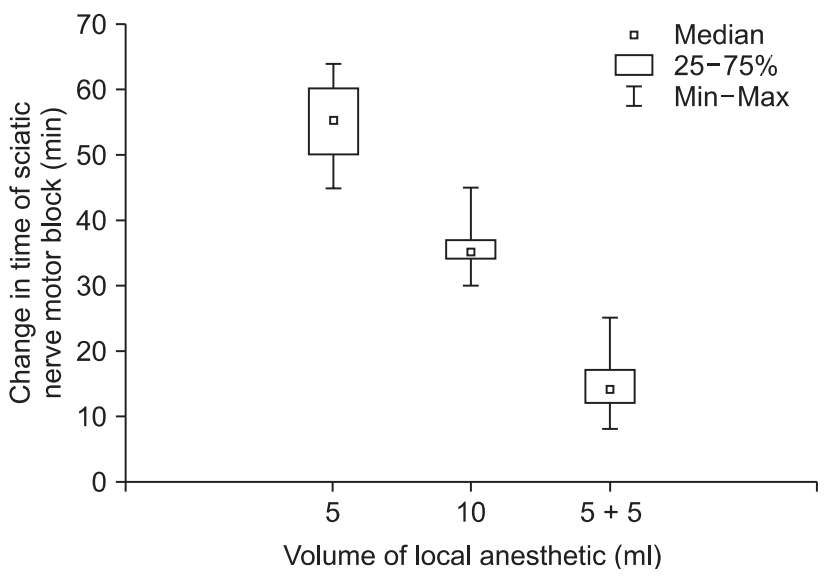

Fig. 2. Change in onset time of sciatic nerve motor block achievement depending on the applied solutions. Horizontal axis: the kind of solution $(5 \mathrm{ml}=5 \mathrm{ml}$ of $0.75 \%$ ropivacaine; $10 \mathrm{ml}=10 \mathrm{ml}$ of $0.75 \%$ ropivacaine; $5+5=$ mixture of $5 \mathrm{ml}$ of $0.75 \%$ ropivacaine and $5 \mathrm{ml}$ of $1 \%$ lidocaine); vertical axis: time of motor block, approaching min.

non-neural tissue there is, the slower the anesthesia develops because the connective tissue is a barrier for local anesthetic diffusion. Considering that the diameter of the sciatic nerve is several times larger than that of the nerves of the humeral plexus in the axillary area, the amount of local anesthetic $(\mathrm{mg})$ will likely influence the time of its diffusion through the sheath of nerves with larger diameters. According to Sala-Blanch et al. [17], during sciatic nerve block in the popliteal pit area by using the application of $20 \mathrm{ml}$ of $1.5 \%$ mepivacaine, the anesthesia of the nerve developed after $15 \mathrm{~min}$. The data collected by Taboada Muniz et al. [15] in terms of the influence of different volumes and concentrations of the time for block development, along with our application of ropivacaine (as an anesthetic agent with a subsequent effect), explain the longer time required for complete sensory and motor block development in groups $\mathrm{A}$ and B [sensory block: $45(40-48)$ and $30(28-30) \mathrm{min}$ accordingly]. Thus, the available published data are discrepant and diverse. Our results are similar to the results described by Riazi et al. [14]. It is evident that the question about the effect of local anesthetic volume and amount of time required for peripheral nerve block development (in particular, the sciatic nerve) needs additional investigation.

The rate of complete development of sciatic nerve block was higher in group $\mathrm{B}$, as explained by the application of the mixture of lidocaine and ropivacaine that we proposed. This mixture contained $50 \mathrm{mg}$ of lidocaine and $37.5 \mathrm{mg}$ of ropivacaine. It is evident that the need for adjuvant epinephrine in addition to the anesthetics mixture in previous research [3] stemmed from the probable summary effect of system toxicity of both anesthetic agents [2] and due to the sciatic nerve block performed in combination with a femoral nerve block. To date, the reduced 
volume and amount of local anesthetic agents per blockage has been impossible because blockades were performed only with the use of an electric stimulator of the peripheral nerves. Thus, the addition of epinephrine to the mixture of anesthetics equilibrates the main advantage of lidocaine. The application of a small quantity and volume of lidocaine and ropivacaine for sciatic nerve block under ultrasonic control decreases the risk of system toxicity of the preparations and removes the need to add epinephrine to the anesthetics mixture. The last factor (absence of epinephrine) promotes faster blockage development.

Thus, we decreased the time for achieving complete sensory block, which has special significance in the everyday anesthetist's practice. Often when a continuous stream of patients comes into the traumatological operating room, the long time required for achieving complete sensory block development leads to starting operations late, which can decrease the effectiveness of operation brigade work.

Contradictory data about block duration depending on local anesthetic volume during the humeral plexus block were obtained by Ponrouch et al. [12] and Gauiter et al. [18]. As Ponrouch et al. noted, humeral plexus block duration decreases as the applied volume of $1.5 \%$ mepivacaine decreases (time of postoperative analgesia was not assessed) [12]. In the humeral plexus block using the interscalene approach, when $5 \mathrm{ml}$ of $0.75 \%$ naropin was applied, block duration (9.9 [5-19] hours) and post-operation analgesia (9.9 \pm 3.7 hours) did not change in comparison with blockades when performed using standard volumes (20-30 $\mathrm{ml}$ ) of $0.75 \%$ ropivacaine [18]. In the sciatic nerve block, we obtained results similar to those of Gauiter et al. [18]. It is possible that analgesia time duration does not depend on the amount of local anesthetic, if this amount is higher than the critical one. However, this question requires more detailed research. In conclusion, we demonstrated that the mix of ropivacaine ( $5 \mathrm{ml}$ of $0.75 \%, 37.5 \mathrm{mg}$ ) and lidocaine (5 $\mathrm{ml}$ of $1 \%$, $50 \mathrm{mg}$ ) leads to a sufficient decrease in the time required for complete sensory and motor block development during sciatic nerve blockade, with no decrease in the time required for postoperation analgesia. The mechanism of such an effect requires additional research.

\section{References}

1. Fanelli G, Casati A, Beccaria P, Aldergheri G, Berti M, Tarantino F, et al. A double-blind comparison of ropivacaine, bupivacaine, and mepivacaine during sciatic and femoral nerve blockade. Anesth Analg 1998; 87: 597-600.

2. Neuburger M, Büttner J. Complications of peripheral regional anesthesia. Anaesthesist 2011; 60: 1014-26.

3. Cuvillon P, Nouvellon E, Ripart J, Boyer JC, Dehour L, Mahamat A, et al. A comparison of the pharmacodynamics and pharmacokinetics of bupivacaine, ropivacaine (with epinephrine) and their equal volume mixtures with lidocaine used for femoral and sciatic nerve blocks: a doubleblind randomized study. Anesth Analg 2009; 108: 641-9.

4. Gioia L, Prandi E, Codenotti M, Casati A, Fanelli G, Torri TM, et al. Peribulbar anesthesia with either 0.75\% ropivacaine or a $2 \%$ lidocaine and $0.5 \%$ bupivacaine mixture for vitreoretinal surgery: a double-blinded study. Anesth Analg 1999; 89: 739-42.

5. Chelly JE. Peripherial nerve blocks: a color atlas. 3rd ed. Philadelphia, Wolters Kluwer/Lippincott Williams \& Wilkins. 2009, pp 1-474.

6. Howell P, Davies W, Wrigley M, Tan P, Morgan B. Comparison of four local extradural anaesthetic solutions for elective caesarean section. Br J Anaesth 1990; 65: 648-53.

7. Marhofer P, Greher M, Kapral S. Ultrasound guidance in regional anaesthesia. Br J Anaesth 2005; 94: 7-17.

8. Andersen HL, Andersen SL, Tranum-Jensen J. Injection inside the paraneural sheath of the sciatic nerve: direct comparison among ultrasound imaging, macroscopic anatomy, and histologic analysis. Reg Anesth Pain Med 2012; 37: 410-4.

9. Hadzic A, Karaca PE, Hobeika P, Unis G, Dermksian J, Yufa M, et al. Peripheral nerve blocks result in superior recovery profile compared with general anesthesia in outpatient knee arthroscopy. Anesth Analg 2005; 100: 976-81.

10. Taboada M, Rodríguez J, Valiño C, Carceller J, Bascuas B, Oliveira J, et al. What is the minimum effective volume of local anaesthetic required for sciatic nerve blockade? A prospective, randomized comparison between a popliteal and a subgluteal approach. Anesth Analg 2006; $102: 593-7$.

11. Latzke D, Marhofer P, Zeitlinger M, Machata A, Neumann F, Lackner E, et al. Minimal local anaesthetic volumes for sciatic nerve block: evaluation of ED 99 in volunteers. Br J Anaesth 2010; 104: 239-44.

12. Ponrouch M, Bouic N, Bringuier S, Biboulet P, Choquet O, Kassim M, et al. Estimation and pharmacodynamic consequences of the minimum effective anesthetic volumes for median and ulnar nerve blocks: a randomized, double-blind, controlled comparison between ultrasound and nerve stimulation guidance. Anesth Analg 2010; 111: 1059-64.

13. Janzen PR, Vipond AJ, Bush DJ, Hopkins PM. A comparison of $1 \%$ prilocaine with $0.5 \%$ ropivacaine for outpatient-based surgery under axillary brachial plexus block. Anesth Analg 2001; 93: 187-91.

14. Riazi S, Carmichael N, Awad I, Holtby RM, McCartney CJ. Effect of local anaesthetic volume (20 vs $5 \mathrm{ml}$ ) on the efficacy and respiratory consequences of ultrasound-guided interscalene brachial plexus block. Br J Anaesth 2008; 101: 549-56.

15. Taboada Muñiz M, Rodríguez J, Bermúdez M, Valiño C, Blanco N, Amor M, et al. Low volume and high concentration of local anaesthetic is 
more efficacious than high volume and low concentration in Labat's sciatic nerve block: a prospective, randomized comparison. Anesth Analg 2008; 107: 2085-8.

16. Moayeri N, Groen GJ. Differences in quantitative architecture of sciatic nerve may explain differences in potential vulnerability to nerve injury, onset time, and minimum effective anesthetic volume. Anesthesiology 2009; 111: 1128-34.

17. Sala-Blanch X, de Riva N, Carrera A, López AM, Prats A, Hadzic A. Ultrasound-guided popliteal sciatic block with a single injection at the sciatic division results in faster block onset than the classical nerve stimulator technique. Anesth Analg 2012; 114: 1121-7.

18. Gautier P, Vandepitte C, Ramquet C, DeCoopman M, Xu D, Hadzic A. The minimum effective anesthetic volume of $0.75 \%$ ropivacaine in ultrasound-guided interscalene brachial plexus block. Anesth Analg 2011; 113: 951-5. 